\title{
Editorial: Resisting Rural Appropriation: Embracing agroecology to transform globalization
}

\author{
STEFANO PRATO
}

As the international community launches the implementation of the recently adopted 2030 Agenda for Sustainable Development, it is essential to advance a deeper understanding of which concepts of rural development such new agenda might promote and which transformative processes it might catalyze. Many are extremely concerned by the productivist approach that the new agenda seems to embody and the pervasive role of the corporate sector in both its design and the current plans for implementation. There is therefore a concrete risk that rural transformation may be driven more by the hegemonic and homogenizing global food system, including industrial agriculture and intensive livestock breeding, rather than by rural communities, including smallholders, pastoralists and other peasants. The benign pretence that these two alternative visions of life, production and markets, can cohabit is debunked daily by the evidence of the predatory nature of the industrial system, with its continued grabbing of land, water and genetic resources, and its profound impact on urban consumers and their dietary preferences. The new Sustainable Development agenda, with its silence on rights and its climate-smart agriculture, could therefore be seen as a conceptual framework deployed to actually contrast the centrality of the right to adequate food and nutrition and the visions of agroecology and food sovereignty embraced by peasants and their social movements. Others, however, indulge in a more benign reading of the new development framework and hope that it will be helpful in advancing a rural agenda. This Journal explores some of these issues and, without any excessive focus on the 2030 Agenda for Sustainable Development, explores visions and challenges related to rural modernity and transformation.

The global policy debate on rural transformation, while undoubtedly not new, acquired new vigour over the past few years in response to the perceived urban bias in the discussions that led to the endorsement and immediate follow-up of the 2030 Agenda. While in many instances well-intended in its original concerns, it has subsequently taken some concerning spins for all those concerned with people-centred development patterns based on food sovereignty. This Journal interrogates the conventional understanding of rural transformation (singular) and explores alternative pathways. The analyses expose a concerning reality: the rural space is-many 


\section{Development 58(2-3): Upfront}

would say continues to be- the battlefield among opposing views of modernity, spanning across ways of life, social and political relations, organization of production and relationship with our ecology.

The starting point of this intellectual journey remains the incontestable fact that rural areas are too often the locus of inacceptable levels of human suffering and deprivation. However, the same can now be said for the peri-urban and even urban space. Hence, there is the need to overcome a stereotyped view of rural backwardness versus urban modernity. Many urban/rural analyses are still based on comparing average figures between these two spaces, constructing the false notion of an average urban citizen that does not exist in reality. No doubt there is also the impact of significant rural-urban migrations and the continued advancement of urbanization, and most frequently 'metropolization'. However, the pull and push factors of these massive movements should be better analyzed before considering them as a de-facto reality. Nevertheless, urban poverty and marginalization are rapidly on the rise as the expectations for better-paid, non-farm urban jobs are revealing their untenable foundations.

Demystifying stereotypes of rural backwardness is therefore the first conceptual step that allows for the emergence of new visions for the rural space. In this respect, one has often the impression that the 'rural' is considered as the primitive version of the 'urban' in an underdeveloped context, almost as development moves linearly from the rural to the urban reality. Indeed, the concept of rural modernity might be considered an oxymoron by many within global policy circles. But this is exactly where a significant part of the rural transformation narrative problem resides. This narrative is largely shaped away from the rural spaces themselves with limited, if at all, participation of the primary subjects that would need to design and drive any local transformative process. In fact, the narrative often contrasts and contradicts the alternative visions that communities may have of their possible development trajectories.

The agency question is therefore fundamental as it defines the legitimacy of a vision of rural 156 transformation and localizes it within a precise locus and context. Beyond the illegitimacy of a rural transformation agenda that does not spring from the rural space itself, four biased narratives influence to varying degrees the current conceptualizations of rural transformation processes within global policy debates. First, the grand narrative of feeding the planet and the need to boost production and productivity with significant investments in agribusiness, despite the reality that smallholders currently supply up to 70 percent of the overall food production (CSM, 2016). Furthermore, according to the Save Food Initiative of the Food and Agriculture Organization (FAO), every year around the globe, 1.3 billion tonnes of food is lost or wasted-that is one-third of all food produced for human consumption (FAO, 2016). The so-called industrialized countries waste almost as much food as the entire net food production of sub-Saharan Africa on annual basis and the amount of food lost and wasted every year is equal to more than half of the world's annual cereal harvest.

The second biased narrative is related to the climate challenge and the pressure for agriculture to adapt to it through technological, and often biotechnological, solutions. Indeed, sometime ones feel that climate change must be coming from outer space. The latest report of the HighLevel Panel of Expert (HLPE) of the Committee on World Food Security (CFS) states that the livestock sector alone, as a driver of deforestation, demand for feed, and transportation and processing infrastructure, is directly and indirectly responsible for 14.5 percent of greenhouse gas emissions (GHG) emissions. Together, permanent meadows, pastures and land dedicated to the production of feed thus represent 80 percent of total agricultural land (HLPE, 2016). Against the evident need for de-intensification, the narrative uses, abuses and ultimately corrupts the concept of sustainability to justify the unjustifiable: the obvious conundrums of sustainable intensification and technologydriven climate smart-agricultures become the new Trojan horses to propose biotechnologies that allows the continued expansion of the industrial agriculture that is itself the origin of the biodiversity loss and the climate implications that these false solutions claim to address. 
Thirdly and most recently, the push for nutrition-sensitive agriculture that instrumentalizes old and emerging nutritional challenges to propose food fortification, including bio-fortification. Rather than promoting diversified diets based on agro-biodiversity, this narrative fails to recognize that nutritional deficits will inevitably result from increasingly homogenous diets largely composed of industrial products based on large scale agriculture of very few crops. It is the reduction of biodiversity and nutritional food content that is inherently consequent to the industrial system that generates the nutritional deficiencies that are claimed to require food fortification. The industrial system claims to offer food fortification as the solution to a problem it has itself generated and, by doing so, it continues to squeeze and erode local food systems that rather offer deeply rooted solutions based on agro-biodiversity.

Fourth and last is the mirage of structural transformation that calls for people to move out of agriculture and engage in better paid industrial and service-based employment. It is too bad that these jobs only seem to exist in fiction. The pattern of structural transformation that characterized past experiences of industrialization does not seem to be replicable by today's commodity trapped economies. Established productive capacities and increasingly mono-directional trade liberalization are generating new patterns of de-industrialization and premature tertiarization of the developing economies, particularly within the African continent, that fall dramatically short of the claimed employment expectations. Furthermore, one also needs to factor in the radically different extent of labour intensity that new productive technologies, including the extensive application of robotics, are fast tracking globally.

The combined effect of the agency fallacy and these biased narratives means that the paradigm of rural transformation may risk becoming yet another instrument of rural appropriation, further advancing the tremendous and continuing rise in intensive industrial agriculture and its rapid consolidation globally, and augmenting the continued process of economic and political concentration in few hands, which is shrinking dramatically the space for small-scale food producers and generating extensive disempowerment of both producers and workers. This is where the blindness of conventional poverty analyses to the dynamics of accumulation and concentration of wealth is instrumental to the capture of power of ruling elites. Hence the power of the descriptive, analytical and normative framework of inequalities in exposing the nexus between poverty and prosperity and all related political economies (Prato, 2014). In this context, the nexus between predatory economy, shrinking democratic space and security state is also increasingly evident, leading to the emergence of some type of neo-feudal state, as opposed to the long-claimed developmental state, animated by a false morality while it is in fact using moral imperatives to increasingly acquire control of resources, constrain democratic institutions and master security to limit liberties by pretending to protect citizens against enemies it has itself invented. This is the great challenge of our times: The State is the primary perpetrator of injustice while at the same time, it remains the key instrument to redress it.

Alternative pathways are clear. Present food systems are dysfunctional because they result in unhealthy diets, unsustainable ecological footprints and impoverishments of small-scale producers. They are the outcome of a supply driven and macroeconomic approach to commodified food. The alternatives are based on locally rooted and driven processes that promote agroecological diversification and food sovereignty. This calls for public investments and supporting policies for those that are already feeding the world in manners that can increasingly protect and enhance biodiversity, heal our planet, promote healthy and diversified diets based on traditional and resilient crops, and strengthen local territorial markets and circular economies. In this respect, the rural space is the last bastion of resistance against the hegemonic and hegemonizing global economy that is increasing dematerializing and de-humanizing the experience of life. But it is not only a locus of resistance. It is also a dynamic space for the re-invention of production and social relations and a vibrant 


\section{Development 58(2-3): Upfront}

laboratory for experimentation of old new solutions that can transform our lives and redress our current challenges into precious opportunities to rediscover the knowledges, identities and traditions that made our common humanity.
The real challenge is not that of rural transformation, but rather that of rurality to resist the current wave of dysfunctional globalization and transform our lives and social relations. Back to the rural future!

\section{References}

Civil Society Mechanism (CSM) to the Committee on World Food Security (CFS) (2016) 'Connecting Smallholders to Market - An Analytical Guide', October.

FAO (2016) FAO SAVE FOOD: Global Initiative on Food Loss and Waste Reduction, http://www.fao.org/save-food/ resources/infographic/en/

HLPE (2016) 'Sustainable agricultural development for food security and nutrition: what roles for livestock?', A report by the High Level Panel of Experts on Food Security and Nutrition of the Committee on World Food Security, Rome.

Prato Stefano (2014) 'Editorial: The Struggle for Equity: Rights, food sovereignty and the rethinking of modernity', Development 57(3-4): 311-319. 